\section{RELATIONSHIP BETWEEN NURSING HOME SAFETY CLIMATE AND CAREGIVERS' COMPETENCE}

\author{
Jaana SEPP' \& Marina JÄRVIS ${ }^{2}$ \\ ${ }^{1}$ Tallinn Health Care College, Tallinn, Estonia \\ ${ }^{2}$ Tallinn University of Technology (TalTech), Tallinn, Estonia \\ Corresponding author e-mail: jaana.sepp@ttk.ee
}

\begin{abstract}
To provide quality healthcare, strong teamwork, safety commitment and collaboration between workers are needed. The aim of this paper is to analyse factors related to safety climate and professional competence among caregivers and to compare the results between different age groups in Estonian nursing homes. A Nordic Safety Climate Questionnaire (NOSACQ-50), measuring 7 dimensions of safety climate, was used in order to assess caregivers' perceptions of the safety climate in Estonian nursing homes, on a sample of 233 caregivers. In order to supplement results from the safety climate study, a Caregivers' Competence Questionnaire (CCQ) measuring 6 scales of the caregivers' competences, their perceptions towards received education and safety-related procedures in nursing homes, was used on a sample of 241 caregivers. Results show differences between age groups of caregivers. The most experienced caregivers tended to have a better understanding of their specialty and more positive ratings of the dimensions of safety climate and safety commitment than younger age groups of caregivers. Result show that the age group with respondents born in the period of 1961-1970 gave more positive ratings of "Necessary skills, knowledge in living questions and caring activities" than did other groups of caregivers (mean $=4.46$ and 4.41) and of "First aid" (mean $=4.47$ ). The study sheds new light on the usability and applicability of the existing assessment tools NASACQ-50 and CCQ. Interventions to promote safety climate in the nursing homes should be tailored to the target group with a special focus on age and work experiences as attitudes and perceptions may differ among those groups.
\end{abstract}

Keywords: Caregivers, Competences, Nursing homes, NOSACQ-50, CCQ Safety Climate.

JEL Classification: J14, J28

\section{INTRODUCTION}

To provide patients' and employees' safety and quality of care, we need to know how age aspects influence workers' commitment to safety and open communication in nursing homes. The aim of this paper is to analyse factors related to safety climate, safety knowledge, open communication and professional competence among caregivers' age aspects in Estonian nursing homes.

Study includes two parts and took place in the period from 2016 to 2017. Two validated questionnaires were used in 15 Estonian nursing homes. In order to 
measure caregivers' perceptions of safety climate, a Nordic Safety Climate Questionnaire (NOSACQ-50) was used. Caregivers' perceptions about their education were evaluated by the Caregivers' Competence Questionnaire (CCQ). It is essential to mention here that answers from two different questionnaires were merged not on individual's level but based on age groups. If it were possible to find exact answers of all individuals from two samples and merge them on individual's level, then it could be assumed that some relations could be defined within factors.

This study was carried out in a single healthcare system (nursing homes), and therefore, the results cannot be generalised to other hospital systems. The quantitative data were self-reported, which was affected by information bias and recall bias. As all the data in this study were gathered from a single country, Estonia, it posed some limitations to the generalisability of the results. However, the results are in these terms somewhat generalisable to other countries, such as the Baltic countries as post-communist newer European Union Members, where there are similar healthcare and legal systems, as well as common history.

\section{BACKGROUND}

Nowadays, healthcare workforce encompasses a wide variety of several generations that need to work together (Moore et al., 2016). It is essential to create such workplace culture within the healthcare organisation that encourages all employees of different generations to form teams, to cooperate and to work together, to share their knowledge and expertise in order to deliver effective healthcare and meet patient needs and outcomes. Healthcare is a complicated field; there are many bottlenecks, such as the lack of specialists, high responsibility and time pressure, high physical and emotional demands, an aging workforce, subordination, depersonalization, poor working conditions as well as weak teamwork, organisational (safety) climate and bad communication (Kim et al., 2010; Woodhead et al., 2014; Sepp \& Tint, 2017). A positive safety climate, education and awareness, management commitment to safety are critical aspects to keeping healthcare workers safe on their job and also known as leading indicators of healthcare worker safety behaviours and high quality and the sustainability of provided healthcare services (West et al., 2006; Sepp et al., 2018; Atstaja, et al., 2017; Titlestad et al., 2018). Previous studies also show that a low level of safety culture correlates with patient safety and quality of care and depends on the efficiency of a safety system within an organisation (Ratnapalan \& Uleryk, 2014).

A strong instrument for an effective safety management system in health care is a high level of safety culture, which is based on shared organisational values and good safety knowledge (Ostrom et al., 1993; Zohar, 2008; Järvis et al., 2016). According to previous studies, organisations should integrate such a safety management system that prevents not only injuries and hazards (Haight et al., 2014; Ratnapalan \& Uleryk, 2014; Lambert, 2004), but also encourages open communication, cooperation, organisational learning (Ratnapalan \& Uleryk, 2014; Hamdam, 2013) and teamwork, as well as enhances worker's safe behaviour and workers' and patients' safety (Flin, 2007; Sepp, 2018; Pousette et al., 2017; Hamdam, 2013; West et al., 2006). One barrier for communication may be a 
difference among workers of different ages. All enterprises should prevent generational misunderstandings and teach their employees to communicate openly (Cos \& Holloway, 2011).

Based on the generation theory, it can be concluded that people from the same age group perceive the same activities similarly. It is based on "generational context" (Mannheilm, 1952), which is stipulated as the collective memories (Halbwachs, 1980) and is affected by values, attitudes and preferences of the generation (Schuman \& Scott, 1989). In addition, the cultural background of different generations can create barriers to open communication, because each age group has their own value system (Cox \& Holloway, 2011). Theoretically, it is possible to define five different generations: "Silent Generation or Traditionalists" who were born in 1946 or the end of World War II; "Baby Boomers", who were born between 1946 and 1960. Historically, these generations are called children of "Great War survivors". "Generation X (Xers)" born between 1960 and 1980 and "Generation Y" or "Millennials" born between 1980 and 1995 have been kept as children on Baby Boomers (Foot \& Stoffman, 1998; Reeves \& Oh, 2008). The latest generation born after 1995 called "Generation Z" is the age group who is least represented in the labour market (Reeves \& Oh, 2008). Studies have demonstrated that "Generation Y" is different from previous generations (Ng \& Parry, 2016) because they have higher expectations of themselves, their ability for development and lifestyle aspirations, doing their future career, and require a special prospective of employers (Hill, 2002; Ng et al., 2010; Westman et al., 2011; Arora \& Dhole, 2019). Studies show that there are generation differences in the work values (Cox \& Holloway, 2011; Smola \& Sutton, 2002). The younger generation is less loyal and expresses lower work centrality; they also assume fast promotion at work and more possibilities for development. The older workers attach higher importance to their work and view work as an important part of their lives. For "Silent Generation", status and independence at work are more valuable than for younger workers ("Baby Boomers", "Gen Xers"). Younger workers feel that relations at work, work conditions, wellbeing and security are more valuable for them (Hansen \& Leuty, 2012). Studies show that "Millennials" representatives of "Generation X" appreciate extrinsic work values, while older generations value prestige of work (Twenge et al., 2010; Krahn \& Galambos, 2014).

It is important to understand that for human resource management (HRM), there are three main aspects that relate to age differences and workers' behaviour ( $\mathrm{Ng} \&$ Parry, 2016; Kuimet et al., 2016). First, organisations should find the best way to recruit and hold the "Millennials". Second, younger generation does not follow the traditional career way and creates their own path (McDonald \& Hite, 2008). Third, the differences in work values may cause generational conflicts, which are based on different expectations, work ethics, attitudes, and motivations (Glass, 2007). The current study is based on the third aspect. The differences mentioned between generations give us a signal that generational differences can influence understanding of safety issues and patient safety (Moore et al., 2016). Based on this consideration, labour market is getting older and "Millennials" will be managing the aging workforces, the different expectations of the generations may cause conflicts in the workplace (Arnold \& Yue, 2012). In order to avoid these problems, 
it is essential not only to create such a working environment where workers are motivated to work together and support the activities and mission of organisation, but also to develop employees' multigenerational skills, such as knowledge transfer, inclusion, conflict solving, open communication, and trust. All named skills are related to each other and based on open communication and trust (Cox \& Holloway, 2011) (see Fig. 1).

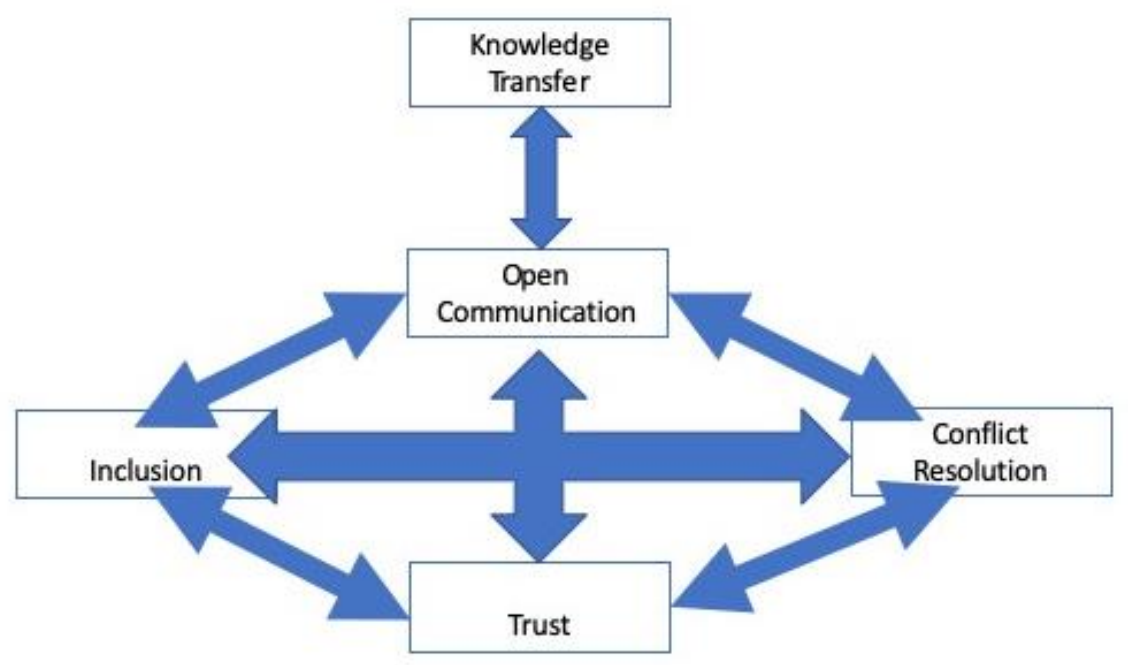

Fig. 1. Interrelatedness of multigenerational skills (Cox \& Holloway, 2011).

However, these skills could be implemented and used when organisational culture, blame-free and non-punitive environment would support it. Open communication, teamwork and commitment to safety are the criteria, which support blame-free culture, minimise barriers among workers (Harrington \& Smith, 2015), and enhance an understanding of communication, inclusion, trust and respect. Open communication also plays the transferring role between trust and knowledge transfer, which is the most important aspect within safety culture (Sepp \& Tint, 2017) where workers can learn from mistakes operatively (Alameddine et al., 2015).

Although many studies link patients and employees' safety to the quality of care, no evidence has been provided that links different factors of safety climate to caregivers' age and professional competences. The present study addresses this gap by providing evidence linking safety perceptions in nursing home workers (caregivers) to different factors of safety climate, such as safety management, safety commitment, safety communication and learning, and further finds a linkage between different age groups and caregivers' professional competence. The aim of this paper is to analyse factors related to safety climate, safety knowledge, open communication and professional competence among caregivers' age aspects in Estonian nursing homes. 


\section{METHODS}

\subsection{Study Design and Sample}

A cross-sectional survey was conducted in 15 Estonian nursing homes. Two questionnaires were administered anonymously to all caregivers working in different nursing homes. The participation was voluntary; the cover paper includes all information about the study background and participation. The first questionnaire measuring different aspects of safety climate was the Nordic Safety Climate Questionnaire (NOSACQ-50) (Kines et al., 2011). In the samples, nursing homes with rehabilitation and follow-up healthcare services were involved. The data were collected in 2016. The questionnaire was completed by 233 respondents (the response rate was $63 \%$ ). The second part of the survey was carried out in 2017 and included the assessment of caregivers' competences from the same Estonian nursing homes. The response rate was $67 \%$ and the questionnaire was completed by 241 caregivers. The data demonstrate that a majority of caregivers in Estonian nursing homes are females at the age of 45-64 years.

\subsection{NOSACQ and CCQ Questionnaires}

To investigate the caregivers' shared perceptions toward safety related procedures and practices in Estonian nursing homes, the NOSACQ-50 questionnaire in the Estonian and Russian languages was used. The questionnaire includes 7 safety climate dimensions: Dim1 - "Management safety priority and ability". The organisational priorities are largely communicated through the managers. Manager's behaviour would be the main source of the information. If the managers are perceived to be committed to safety and to prioritisation of safety in relation to other goals, safe behaviour would be expected to be rewarded, and thereby reinforced. Dim2 - "Management safety empowerment". One way for managers to convey trust is empowering the employees. Empowerment is a delegation of power, and as such, it demonstrates that managers trust workers' ability and judgement, and that managers value workers' contributions. Dim3 "Management safety justice". Employee safety responsibility and safety behaviour would be positively influenced by management procedural and interactional safety justice, i.e., just treatment and procedures when handling accidents and near accidents. Dim4 - "Workers' safety commitment". Safety motivation is strongly determined by the leadership and safety standards of the leader, but also by the standards and group cohesion. Group standards and cohesion are also determined by safety behaviour. Dim5 - "Workers' safety priority and risk non-acceptance". Safety priority and safety commitment should be assessed regarding separately management procedures and practice. Dim6 - "Peer safety communication, learning, and trust in safety ability". Communication and social interaction are a necessary means for the creation of social constructs, such as organisational climate. Reason (1997) pointed out a learning culture and a reporting culture as two of the constituting sub-climates. Hofmann \& Stetzer (1998) suggested that management encouraging open communication on safety sent a strong signal on how safety was valued. Dim7 - "Workers' trust in the efficacy of safety systems". 
The safety climate questionnaire intended for assessment of perceptions of the efficacy of safety systems should assess these together with other aspects of safety climate suggested above (Kines et al., 2011). The NOSACQ-50 contains positively and negatively formulated 50 items using a four-point Likert scale: 1 - strongly disagree, 2 - disagree, 3 - agree, and 4 - strongly agree. The mean score was calculated for each dimension, respondent and for the groups. A mean score over 2.5 was considered a positive result, which was the mathematical mean value of the highest and lowest score.

The Caregivers' Competence Questionnaire (CCQ) was used to explore caregivers' perceptions according to their education (Based on the Estonian National Occupational Standard for Caregivers, Level 4). The questionnaire was previously tested and validated by authors in the Estonian and Russian languages (Sepp et al., 2018). The questionnaire includes six scales: (1) Necessary skills, knowledge in living quests and patient care; (2) Necessary skills, knowledge for coping with the elderly and people with special needs; (3) Commitment to safety; (4) Communication skills; (5) First aid; 6) Awareness of specialty. The data were analysed using the Statistical Package for Social Science (SPSS 24.0) software. The ANOVA, averages and correlations for pre-defined dimensions and scales of each questionnaire were calculated and analysed. In total, seven (7) dimensions from the questionnaire NOSACQ-50 and six (6) scales from the CCQ questionnaire were analysed. The average responses of age groups from both questionnaires for all scales and dimensions were calculated.

\section{RESULTS}

The correlations between the dimensions within the two questionnaires according to the age groups were analysed and presented in Table 1.

Table 1. The Average Responses of Different Dimensions of Safety Climate by Age Groups

\begin{tabular}{|c|c|c|c|c|c|c|}
\hline \multirow{2}{*}{$\begin{array}{c}\text { Dimensions of } \\
\text { NOSACQ-50 } \\
(233 \\
\text { respondents })\end{array}$} & \multicolumn{6}{|c|}{ Age group } \\
\hline & $\begin{array}{c}1 \\
1941-1950\end{array}$ & $\begin{array}{c}2 \\
1951-1960\end{array}$ & $\begin{array}{c}3 \\
1961-1970\end{array}$ & $\begin{array}{c}4 \\
1971-1980\end{array}$ & $\begin{array}{c}5 \\
1981-1990\end{array}$ & $\begin{array}{c}6 \\
1991-2000\end{array}$ \\
\hline Dim1 & 3.54 & 3.39 & 3.36 & 3.36 & 3.25 & 3.70 \\
\hline Dim2 & 3.72 & 3.52 & 3.41 & 3.51 & 3.23 & 3.62 \\
\hline Dim3 & 3.80 & 3.55 & 3.40 & 3.43 & 3.51 & 3.81 \\
\hline Dim4 & 3.79 & 3.52 & 3.56 & 3.56 & 3.58 & 3.58 \\
\hline Dim5 & 2.94 & 2.82 & 2.91 & 2.93 & 2.96 & 2.99 \\
\hline Dim6 & 3.58 & 3.57 & 3.50 & 3.49 & 3.35 & 3.69 \\
\hline Dim7 & 3.55 & 3.62 & 3.64 & 3.60 & 3.56 & 3.62 \\
\hline \multicolumn{7}{|c|}{ Scales of CCQ (241 respondents) } \\
\hline Scale 1 & 4.32 & 4.27 & 4.46 & 4.28 & 4.21 & 4.17 \\
\hline Scale 2 & 4.33 & 4.26 & 4.41 & 4.25 & 4.27 & 3.96 \\
\hline Scale 3 & 4.08 & 4.27 & 4.16 & 3.95 & 3.83 & 3.85 \\
\hline Scale 4 & 3.78 & 4.13 & 4.15 & 4.18 & 3.90 & 4.03 \\
\hline Scale 5 & 4.17 & 4.32 & 4.47 & 4.13 & 4.03 & 4.10 \\
\hline Scale 6 & 4.61 & 4.18 & 4.38 & 4.19 & 3.98 & 4.03 \\
\hline
\end{tabular}


Table 2 presents the results focused on the correlations between the dimensions in the questionnaire NOSACQ-50.

Table 2. Correlations of Dimensions from the Questionnaire NOSACQ-50

\begin{tabular}{|l|l|l|l|l|l|l|l|}
\hline \multicolumn{1}{|c|}{$\begin{array}{c}\text { Dimensions NOSACQ-50 } \\
\text { (N= 233) }\end{array}$} & Dim1 & Dim2 & Dim3 & Dim4 & Dim5 & Dim6 & Dim7 \\
\hline Dim1 & 1 & & & & & & \\
\hline Dim2 & $0.520^{* *}$ & 1 & & & & & \\
\hline Dim3 & $0.509^{* *}$ & $0.582^{* *}$ & 1 & & & & \\
\hline Dim4 & $0.404^{* *}$ & $0.355^{* *}$ & $0.386^{* *}$ & 1 & & & \\
\hline Dim5 & $0.324^{* *}$ & $0.187^{*}$ & $0.238^{* *}$ & $0.341^{* *}$ & 1 & & \\
\hline Dim6 & $0.410^{* *}$ & $0.517^{* *}$ & $0.403^{* *}$ & $0.386^{* *}$ & $0.168^{*}$ & 1 & \\
\hline Dim7 & $0.244^{* *}$ & $0.245^{* *}$ & $0.217^{* *}$ & $0.339^{* *}$ & 0.141 & $0.301^{* *}$ & 1 \\
\hline
\end{tabular}

**Statistically significant $p$-values $(p<0.01)$

*Statistically significant $p$-values $(p<0.05)$

The results from the NOSACQ-50 questionnaire revealed that there was a moderate strong positive correlation between "Management safety priority and ability" (Dim1) and "Management safety empowerment" (Dim 2) $(r=0.520)$. It means that the main aspects of safety climate (Dim2 and Dim3) of management safety empowerment and management safety justice correlate with how the perceived degree to which employers respectively empower their workers influences aspects of their own safety and deals with occupational health and safety incidents fairly as well as justly. All correlations are positive, and almost all of them are significant (with an exception of correlation between Dim5 and Dim7; this correlation is not statistically significant). Moderate strong positive correlation is between Dim1 and Dim2 $(r=0.520)$, Dim1 and Dim3 $(r=0.509)$, Dim2 and Dim3 $(r=0.582)$.

Participants responded to the CCQ questionnaire based on their self-appraisal of one's efficacy in their everyday tasks in caregiving and evaluated how much they believed that they had learned how to deal with different situations (Table 3).

Table 3. Relationships between Different Scales from the Competence Questionnaire

\begin{tabular}{|l|l|l|l|l|l|l|}
\hline & \multicolumn{1}{|c|}{ Scale1 } & \multicolumn{1}{|c|}{ Scale2 } & \multicolumn{1}{|c|}{ Scale3 } & \multicolumn{1}{c|}{ Scale4 } & \multicolumn{1}{c|}{ Scale5 } & Scale6 \\
\hline Scale 1 & 1 & & & & & \\
\hline Scale 2 & $0.780^{* *}$ & 1 & & & & \\
\hline Scale 3 & $0.685^{* *}$ & $0.678^{* *}$ & 1 & & & \\
\hline Scale 4 & $0.687^{* *}$ & $0.674^{* *}$ & $0.597^{* *}$ & 1 & & \\
\hline Scale 5 & $0.657^{* *}$ & $0.750^{* *}$ & $0.661^{* *}$ & $0.586^{* *}$ & 1 & \\
\hline Scale 6 & $0.614^{* *}$ & $0.605^{* *}$ & $0.557^{* *}$ & $0.351^{* *}$ & $0.532^{* *}$ & 1 \\
\hline
\end{tabular}

**Statistically significant $p$-values $(p<0.01)$

Data analyses of the results from the questionnaire have demonstrated that all correlations are positive and significant. Mastery and caregiving competence scales exhibited strong positive correlations between Scale 1 "Necessary skills, knowledge in living quests and caring activities" and Scale 2 "Necessary skills, knowledge for coping with the elderly and people with special needs" $(r=0.780)$; 
Scale 1 "Necessary skills, knowledge in living quests and caring activities" and "Scale 3 "Commitment to safety" $(r=0.685)$; Scale 1 "Necessary skills, knowledge in living quests and caring activities" and Scale 4 "Communication skills" $(r=0.687)$ as well as Scale 2 "Necessary skills, knowledge for coping with the elderly and people with special needs" and Scale 5 "First aid" $(r=0.750)$.

\subsection{Comparison of the Age Groups}

Further analyses will compare results from two questionnaires for different age groups. Respondents were grouped into 6 age groups according to their year of birth: group 1) 1941-1950; group 2) 1951-1960; group 3) 1961-1970; group 4) 1971-1980; group 5) 1981-1990; group 6) 1991-2000. Table 4 presents the results of the respondents classified by age groups who responded to the questionnaire CCQ.

Table 4. Relationships between Scales of CCQ Questionnaire by Different Age Groups

\begin{tabular}{|c|c|c|c|c|c|c|c|}
\hline \multirow{2}{*}{\multicolumn{2}{|c|}{ Scales }} & \multicolumn{6}{|c|}{ Age group } \\
\hline & & Group 1 & $\begin{array}{c}\text { Group } 2 \\
1051\end{array}$ & $\begin{array}{c}\text { Group } 3 \\
\end{array}$ & $\begin{array}{c}\text { Group } 4 \\
1071-1080\end{array}$ & $\begin{array}{c}\text { Group } 5 \\
\end{array}$ & Group 6 \\
\hline \multirow{4}{*}{$\begin{array}{l}\text { Scale } \\
1\end{array}$} & Mean & 4.32 & 4.27 & 4.46 & 4.28 & 4.21 & 4.17 \\
\hline & Maximum & 4.80 & 5.00 & 5.00 & 5.00 & 5.00 & 4.70 \\
\hline & Minimum & 3.60 & 1.70 & 3.00 & 2.80 & 1.70 & 3.60 \\
\hline & Mode & 4.80 & 5.00 & 4.80 & 4.70 & 5.00 & 3.90 \\
\hline \multirow{4}{*}{$\begin{array}{l}\text { Scale } \\
2 \\
\end{array}$} & Mean & 4.33 & 4.26 & 4.41 & 4.25 & 4.27 & 3.96 \\
\hline & Maximum & 4.71 & 5.00 & 5.00 & 5.00 & 5.00 & 4.71 \\
\hline & Minimum & 3.86 & 2.29 & 3.14 & 2.43 & 1.43 & 3.57 \\
\hline & Mode & 3.86 & 4.57 & 5.00 & 4.00 & 5.00 & 3.57 \\
\hline \multirow{4}{*}{$\begin{array}{l}\text { Scale } \\
3\end{array}$} & Mean & 4.08 & 4.27 & 4.16 & 3.95 & 3.83 & 3.85 \\
\hline & Maximum & 5.00 & 5.00 & 5.00 & 5.00 & 5.00 & 5.00 \\
\hline & Minimum & 3.00 & 2.00 & 2.00 & 1.00 & 1.50 & 2.50 \\
\hline & Mode & 4.00 & 4.00 & 4.00 & 4.00 & 4.00 & 4.00 \\
\hline \multirow{4}{*}{$\begin{array}{l}\text { Scale } \\
4\end{array}$} & Mean & 3.78 & 4.13 & 4.15 & 4.18 & 3.90 & 4.03 \\
\hline & Maximum & 5.00 & 5.00 & 5.00 & 5.00 & 5.00 & 5.00 \\
\hline & Minimum & 3.00 & 2.00 & 1.33 & 2.33 & 1.67 & 3.00 \\
\hline & Mode & 3.67 & 4.00 & 5.00 & 4.67 & 3.33 & 4.00 \\
\hline \multirow{4}{*}{$\begin{array}{l}\text { Scale } \\
5\end{array}$} & Mean & 4.17 & 4.32 & 4.47 & 4.13 & 4.03 & 4.10 \\
\hline & Maximum & 5.00 & 5.00 & 5.00 & 5.00 & 5.00 & 5.00 \\
\hline & Minimum & 2.67 & 1.33 & 2.00 & 1.67 & 1.67 & 3.67 \\
\hline & Mode & 5.00 & 4.00 & 5.00 & 4.00 & 4.33 & 4.00 \\
\hline \multirow{4}{*}{$\begin{array}{l}\text { Scale } \\
6\end{array}$} & Mean & 4.61 & 4.18 & 4.38 & 4.19 & 3.98 & 4.03 \\
\hline & Maximum & 5.00 & 5.00 & 5.00 & 5.00 & 5.00 & 4.83 \\
\hline & Minimum & 3.83 & 2.17 & 3.00 & 3.17 & 1.00 & 3.33 \\
\hline & Mode & 5.00 & 4.00 & 5.00 & 4.00 & 3.67 & 3.33 \\
\hline
\end{tabular}

Study results showed that, in general, all average responses from different age groups were high, almost always above 4 (4 means "good" on the response scale).

Age group 3 (respondents born in the period of 1961-1970) had the highest average responses on the scales: "Necessary skills, knowledge in living questions 
and caring activities" (average response was 4.46); "Necessary skills, knowledge for coping with the elderly and people with special needs" (average response was 4.41) and "First aid" (average response was 4.47). Age group 4 had the highest average response on the scale "Communication skills" (average response was 4.18).

Respondents born in 1971-1980 had the highest average response, followed by the respondents from other age groups. Respondents from age group 2 (born in 1951-1960) had the highest response rate at the scale "Commitment to safety" (average response was 4.27). On the scale "Awareness of specialty", respondents from age group 1 (born in 1941-1950) - the oldest respondents - had the highest response rate. Results of our study revealed that respondents born in the period of 1981-1991 had the lowest average responses among all age groups on scales "Commitment to safety" (average response was 3.83), "First aid" (average response was 4.03), and "Awareness of specialty" (average response was 3.98). The lowest average responses on the scales "Necessary skills, knowledge in living quests and caring activities" (average response was 4.17) and "Necessary skills, knowledge for coping with the elderly and people with special needs" (average response was 3.96) were at age group 6 (born in 1991-2000).

The same data analyses were calculated for the questionnaire NOSACQ-50 (Table 5).

Table 5. Relationships between the Dimensions of Safety Climate and Different Age Groups

\begin{tabular}{|c|c|c|c|c|c|c|c|}
\hline & \multicolumn{6}{|c|}{ Age group } \\
\hline & & $\begin{array}{c}1 \\
1941-1950\end{array}$ & $\begin{array}{c}2 \\
1951-1960\end{array}$ & $\begin{array}{c}3 \\
1961-1970\end{array}$ & $\begin{array}{c}4 \\
1971-1980\end{array}$ & $\begin{array}{c}5 \\
1981-1990\end{array}$ & $\begin{array}{c}6 \\
1991-2000\end{array}$ \\
\hline \multirow{4}{*}{ Dim1 } & Mean & 3.54 & 3.39 & 3.36 & 3.36 & 3.25 & 3.70 \\
\hline & Maximum & 4.00 & 4.00 & 4.00 & 4.00 & 4.00 & 4.00 \\
\hline & Minimum & 3.00 & 2.22 & 2.33 & 2.33 & 2.56 & 3.33 \\
\hline & Mode & 3.67 & 3.67 & 3.67 & 3.67 & 3.78 & 4.00 \\
\hline \multirow{4}{*}{ Dim 2} & Mean & 3.72 & 3.52 & 3.41 & 3.51 & 3.23 & 3.62 \\
\hline & Maximum & 4.00 & 4.00 & 4.00 & 4.00 & 4.00 & 4.00 \\
\hline & Minimum & 3.14 & 1.57 & 1.57 & 2.57 & 2.29 & 3.29 \\
\hline & Mode & 4.00 & 4.00 & 4.00 & 4.00 & 3.00 & 3.57 \\
\hline \multirow{4}{*}{ Dim3 } & Mean & 3.80 & 3.55 & 3.40 & 3.43 & 3.51 & 3.81 \\
\hline & Maximum & 4.00 & 4.00 & 4.00 & 4.00 & 4.00 & 4.00 \\
\hline & Minimum & 3.00 & 1.67 & 1.17 & 1.83 & 2.00 & 3.50 \\
\hline & Mode & 4.00 & 4.00 & 4.00 & 4.00 & 3.50 & 4.00 \\
\hline \multirow{4}{*}{ Dim 4} & Mean & 3.79 & 3.52 & 3.56 & 3.56 & 3.58 & 3.58 \\
\hline & Maximum & 4.00 & 4.00 & 4.00 & 4.00 & 4.00 & 4.00 \\
\hline & Minimum & 3.00 & 2.17 & 2.33 & 2.17 & 2.20 & 3.00 \\
\hline & Mode & 4.00 & 4.00 & 4.00 & 4.00 & 4.00 & 3.67 \\
\hline \multirow{4}{*}{ Dim5 } & Mean & 2.94 & 2.82 & 2.91 & 2.93 & 2.96 & 2.99 \\
\hline & Maximum & 3.86 & 4.00 & 4.00 & 4.00 & 4.00 & 3.67 \\
\hline & Minimum & 1.86 & 1.67 & 1.71 & 1.43 & 1.86 & 2.14 \\
\hline & Mode & 2.57 & 2.29 & 2.86 & 3.57 & 2.43 & 3.14 \\
\hline \multirow{4}{*}{ Dim6 } & Mean & 3.58 & 3.57 & 3.50 & 3.49 & 3.35 & 3.69 \\
\hline & Maximum & 4.00 & 4.00 & 4.00 & 4.00 & 4.00 & 4.00 \\
\hline & Minimum & 3.00 & 2.25 & 2.25 & 2.75 & 2.63 & 3.50 \\
\hline & Mode & 3.38 & 4.00 & 3.50 & 3.63 & 3.00 & 3.50 \\
\hline
\end{tabular}




\begin{tabular}{|c|l|l|l|l|l|l|l|}
\hline \multirow{4}{*}{$\operatorname{Dim} 7$} & Mean & 3.55 & 3.62 & 3.64 & 3.60 & 3.56 & 3.62 \\
\cline { 2 - 8 } & Maximum & 4.00 & 4.00 & 4.00 & 4.00 & 4.00 & 4.00 \\
\cline { 2 - 8 } & Minimum & 2.57 & 2.57 & 1.71 & 2.17 & 2.43 & 3.29 \\
\cline { 2 - 8 } & Mode & 4.00 & 4.00 & 4.00 & 4.00 & 4.00 & 3.57 \\
\hline
\end{tabular}

Study results showed that the highest average responses on the dimensions "Management safety priority and ability" (average response was 3.70), "Management safety justice" (average response was 3.81), "Workers' safety priority and risk non-acceptance" (average response was 2.99) and "Peer safety communication, learning, and trust in safety ability" (average response was 3.69) were obtained by age group 6 . That age group holds the youngest respondents. The oldest respondents (age group 1) had the highest average responses on the dimensions "Management safety empowerment" (average response was 3.72) and "Worker safety commitment" (average response was 3.79). The highest average response on the dimension "Workers' trust in the efficacy of safety systems" was shown by the respondents from age group 3 (born in 1961-1970). Age group 5 had again the lowest average results among all other groups. Respondents from this age group had the lowest average responses on the dimensions "Management safety priority and ability", "Management safety empowerment" and "Peer safety communication, learning, and trust in safety ability".

\subsection{Analyses of Safety Climate and Mastery Caregiving Competence Scales}

According to our results, no statistically significant correlations were found to be defined between factors from two questionnaires. The reason may be that the topics in the selected questionnaires are not as closely related as it was expected. It is important to mention here that answers from two different questionnaires were merged not on individual's levels but based on age groups. If it were possible to find exact answers of all individuals from two samples and merge them on individual's level, then it could be assumed that some relations within the factors could be defined. The analyses of correlations between different scales did not show relations between the factors. It was decided to try to find relations between the scales (CCQ) using the comparison of mean values of different groups. Detailed results are presented in Tables 6,7 and 8.

The results in Table 6 present the groups where statistical significance was detected. Respondents were grouped in two, based on the responses to questions related to dimensions or scale "Commitment to safety" (CCQ). Group 1 - the respondents who gave positive answers to the questions about "Commitment to safety" (answers "agreed" and "totally agreed"). There were $52(\mathrm{~N})$ respondents who gave positive response to the question about "Commitment to safety" (CCQ) and they also answered to the questions related to Dim1 from (NOSACQ-50); and group 2 - the respondents who disagreed with the selected statements (answers "disagreed" and "totally disagreed"). As questions were not mandatory to answer, not all questions were answered by the same number of respondents. There are small variations in the number of respondents who answered the questions. This group of respondents had standard deviation $\mathrm{SD}=0.42$, which was quite small and indicated that the values (answers to Dim1 questions) within this group of 
respondents who were satisfied with "Commitment to safety" tended to be close to the mean answer, which was in this case 3.44.

There is statistically significant difference between the groups on the responses to questions from dimension 7 "Workers' trust in the efficacy of safety systems" (NOSACQ-50). Respondents who gave positive responses to the statements related to "Commitment to safety" had higher average responses to the questions related to dimension 7 "Workers' trust in the efficacy of safety systems" (NOSACQ-50) than respondents who disagreed with the statements about "Commitment to safety" (CCQ). This difference is statistically significant at the significance level 0.05 .

Table 6. Relationships between Factors of Safety Climate and Scale of Professional Competence "Commitment to Safety" among Caregivers

\begin{tabular}{|c|c|c|c|c|c|c|c|c|}
\hline \multirow{2}{*}{\multicolumn{2}{|c|}{$\begin{array}{l}\text { Scale } 3 \text { Commitment } \\
\text { to safety (CCQ) }\end{array}$}} & \multicolumn{7}{|c|}{ Dimensions of NOSACQ-50 } \\
\hline & & \multirow{2}{*}{$\begin{array}{l}\text { Dim1 } \\
3.44\end{array}$} & \multirow{2}{*}{$\begin{array}{l}\text { Dim2 } \\
3.44\end{array}$} & \multirow{2}{*}{$\begin{array}{l}\operatorname{Dim3} \\
3.40\end{array}$} & \multirow{2}{*}{$\begin{array}{l}\text { Dim4 } \\
3.57\end{array}$} & \multirow{2}{*}{$\begin{array}{l}\operatorname{Dim5} \\
2.99\end{array}$} & \multirow{2}{*}{$\begin{array}{l}\text { Dim6 } \\
3.49\end{array}$} & \multirow{2}{*}{$\begin{array}{c}\operatorname{Dim} 7 \\
3.72\end{array}$} \\
\hline \multirow{3}{*}{ Group 1} & Mean & & & & & & & \\
\hline & $\mathrm{N}$ & 52 & 52 & 50 & 51 & 50 & 51 & 50 \\
\hline & SD & 0.42 & 0.51 & 0.61 & 0.46 & 0.56 & 0.36 & 0.30 \\
\hline \multirow{3}{*}{ Group 2} & Mean & 3.37 & 3.47 & 3.51 & 3.54 & 2.86 & 3.52 & 3.56 \\
\hline & $\mathrm{N}$ & 138 & 137 & 135 & 137 & 137 & 138 & 135 \\
\hline & SD & 0.43 & 0.53 & 0.52 & 0.51 & 0.59 & 0.38 & 0.45 \\
\hline \multirow{3}{*}{ Total } & Mean & 3.39 & 3.46 & 3.48 & 3.55 & 2.89 & 3.51 & 3.60 \\
\hline & $\mathrm{N}$ & 190 & 189 & 185 & 188 & 187 & 189 & 185 \\
\hline & SD & 0.43 & 0.53 & 0.55 & 0.50 & 0.58 & 0.37 & 0.42 \\
\hline
\end{tabular}

Statistically significant $p$-values $(p<0.05)$

Respondents were grouped based on the responses to the questions about "Communication skills" (CCQ) (Table 7).

Group 1 - those respondents who gave positive answers to the questions about "Communication skills" (answers "agreed" and "totally agreed"); and group 2 those respondents who disagreed with the selected statements. There is a statistically significant difference between the groups on the responses to the questions from dimension 5 "Workers' safety priority and risk non-acceptance". Respondents who gave positive responses to the statements related to "Communication skills" had higher average responses to the questions related to dimension 5 "Workers' safety priority and risk non-acceptance" than the respondents who disagreed with the statements about "Communication skills" (NOSACQ-50). This difference is statistically significant at the significance level 0.05 .

Table 7. Relationships between Factors of Safety Climate and Scale of Professional Competence "Communication Skills" among Caregivers

\begin{tabular}{|c|l|c|c|c|c|c|c|c|}
\hline \multirow{2}{*}{$\begin{array}{c}\text { Scale } 4 \text { Communication } \\
\text { Skills (CCQ) }\end{array}$} & \multicolumn{7}{|c|}{ Dimensions of NOSACQ-50 } \\
\cline { 2 - 9 } & Dim1 & Dim2 & Dim3 & Dim4 & Dim5 & Dim6 & Dim7 \\
\hline \multirow{3}{*}{ Group 1 } & Mean & 3.41 & 3.47 & 3.50 & 3.50 & 3.02 & 3.47 & 3.67 \\
\cline { 2 - 9 } & $\mathrm{N}$ & 64 & 63 & 63 & 64 & 63 & 64 & 62 \\
\cline { 2 - 9 } & SD & 0.42 & 0.53 & 0.57 & 0.44 & 0.57 & 0.38 & 0.37 \\
\hline
\end{tabular}




\begin{tabular}{|l|l|c|c|c|c|c|c|c|}
\hline \multirow{4}{*}{ Group 2 } & Mean & 3.38 & 3.46 & 3.47 & 3.57 & 2.83 & 3.53 & 3.57 \\
\cline { 2 - 9 } & $\mathrm{N}$ & 126 & 126 & 122 & 124 & 124 & 125 & 123 \\
\cline { 2 - 9 } & $\mathrm{SD}$ & 0.44 & 0.53 & 0.54 & 0.53 & 0.58 & 0.37 & 0.44 \\
\hline \multirow{3}{*}{ Total } & Mean & 3.39 & 3.46 & 3.48 & 3.55 & 2.89 & 3.51 & 3.60 \\
\cline { 2 - 9 } & $\mathrm{N}$ & 190 & 189 & 185 & 188 & 187 & 189 & 185 \\
\cline { 2 - 9 } & $\mathrm{SD}$ & 0.43 & 0.53 & 0.55 & 0.50 & 0.58 & 0.37 & 0.42 \\
\hline
\end{tabular}

Statistically significant $p$-values $(p<0.05)$

Respondents were grouped by their responses to the questions about "Awareness of specialty" (CCQ) (Table 8). Group 1 - those respondents who gave positive answers to the questions about "Awareness of specialty" (answers "agreed" and 'totally agreed'); and group 2 - those respondents who disagreed with the selected statements. Respondents who gave positive responses to the statements related to "Awareness of specialty" had higher average responses to the questions related to dimension 5 "Workers' safety priority and risk non-acceptance" (NOSACQ-50) than the respondents who disagreed with the statements about "Awareness of specialty". This difference is statistically significant at the significance level 0.1

Table 8. Relationships between Factors of Safety Climate and Scale of Professional Competence "Awareness of Specialty" among Caregivers

\begin{tabular}{|c|c|c|c|c|c|c|c|c|}
\hline \multirow{2}{*}{\multicolumn{2}{|c|}{$\begin{array}{l}\text { Scale } 6 \text { Awareness of } \\
\text { specialty (CCQ) }\end{array}$}} & \multicolumn{7}{|c|}{ Dimensions of NOSACQ-50 } \\
\hline & & \multirow{2}{*}{$\frac{\text { Dim1 }}{3.34}$} & \multirow{2}{*}{$\begin{array}{c}\operatorname{Dim} 2 \\
3.37\end{array}$} & \multirow{2}{*}{$\begin{array}{c}\operatorname{Dim3} \\
3.47\end{array}$} & \multirow{2}{*}{$\begin{array}{c}\text { Dim4 } \\
3.50\end{array}$} & \multirow{2}{*}{$\frac{\operatorname{Dim5}}{3.00}$} & \multirow{2}{*}{$\begin{array}{c}\text { Dim6 } \\
3.47\end{array}$} & \multirow{2}{*}{$\frac{\operatorname{Dim} 7}{3.61}$} \\
\hline \multirow{3}{*}{ Group 1} & Mean & & & & & & & \\
\hline & $\mathrm{N}$ & 60 & 60 & 59 & 59 & 60 & 60 & 59 \\
\hline & SD & 0.44 & 0.59 & 0.50 & 0.53 & 0.59 & 0.37 & 0.42 \\
\hline \multirow{3}{*}{ Group 2} & Mean & 3.41 & 3.50 & 3.49 & 3.57 & 2.84 & 3.53 & 3.60 \\
\hline & $\mathrm{N}$ & 130 & 129 & 126 & 129 & 127 & 129 & 126 \\
\hline & SD & 0.43 & 0.49 & 0.57 & 0.48 & 0.57 & 0.37 & 0.41 \\
\hline \multirow{3}{*}{ Total } & Mean & 3.39 & 3.46 & 3.48 & 3.55 & 2.89 & 3.51 & 3.60 \\
\hline & $\mathrm{N}$ & 190 & 189 & 185 & 188 & 187 & 189 & 185 \\
\hline & SD & 0.43 & 0.53 & 0.55 & 0.50 & 0.58 & 0.37 & 0.42 \\
\hline
\end{tabular}

Statistically significant $p$-values $(p<0.01)$

Our results show that workers' commitment to safety is related to trust in the efficacy of safety management system. We can also conclude that safety priority and workers' safe behaviour depend on the communication skills and workers' competences or awareness of specialty.

\section{DISCUSSION}

The strength of the current study is that it linked caregivers' perceptions on safety climate to the mastery and professional competence as an essential characteristic of good caregiving quality based on different generations. In general, our study results show that all perceptions for professional preparation of caregivers (based on CCQ) from different age groups were high, but the younger (born in 1991-2000) respondents had lower response rates on all scales. 
The fact that younger caregivers perceived their education and specialty less valuable needs more research and exploration. According to our results, respondents from age group 5 (born in1981-1990) had lower results in both questionnaires. Respondents from age group 6 (the youngest respondents involved in research) had the lowest results in questionnaire CCQ related to their competences, but in questionnaire "NOSACQ-50", their average responses were one of the highest. Young respondents were not very confident about their professional knowledge probably due to short experience, but they had a high level of knowledge about safety management, which might mean that young generation paid more attention to safety at work. The youngest respondents had a lack of sufficient skills necessary for coping with the elderly and people with special needs. "Millennials" had the lowest rate in scale committed to safety, communication skills and they did not value their specialty. They also did not feel confident enough to provide the first aid. Additionally, our results showed that the youngest caregivers had the highest average responses on safety climate dimensions related to management safety priority, ability, justice and workers' safety priority, risk nonacceptance, safety communication, learning, and trust in safety ability. The oldest respondents were more committed to safety and had the highest average responses on management safety empowerment. Additionally, older workers trusted more the efficacy of the established safety management systems.

The results showed that older workers felt themselves more mastery and confident on tasks related to first aid and caring activities. More experienced caregivers were more committed to safety and valued their competence. Additionally, our results showed that the experiences at workplace and in personal life influenced workers' understanding of their occupation and increased their competences. Similar results were found by Rasch \& Kowske (2012) who concluded that the younger generation ('Millennials') was less committed to work than "Generation X" and "Baby Boomers" and evaluated their competences lower (Twenge \& Campbell, 2008). It is important to mention that safe workers' behaviour depends on the workers' competence and safety commitment (Sepp et $a l ., 2018$ ), which are closely related to HRM and workers' sustainable development (Ratnapal \& Uleryk, 2014; Kuimet et al., 2016). Workers' continuous training supports them in daily life and gives opportunity to protect themselves and provide safety for clients and co-workers (Chan et al., 2014; Ahanchian et al., 2015; Heydary et al., 2016).

Our study results revealed that caregivers who were committed to safety trusted the efficacy of the established safety management system. In addition, the results demonstrated that caregivers' trust of safety management systems depended on workers' experiences and confidence in communication abilities. Additionally, we can say that the "Awareness of specialty" relates to safety priority and workers' safe behaviour. This is in a line with previous research conducted in the healthcare sector (McGonagle et al., 2016; Gurses et al., 2009). 


\section{CONCLUSION}

The aim of this study was to investigate factors related to safety climate, safety knowledge, open communication and professional competence among caregivers' age. The current study revealed how safety climate and professional competence of caregivers were perceived across generations. The findings suggested that interventions to promote safety climate in the nursing homes should be tailored to the target group of caregivers with a special focus on their age and work experiences as attitudes and perceptions might differ among different groups. Evidence was found that the most experienced caregivers tended to have a better understanding of their specialty and more positive ratings of the dimensions of safety climate and safety commitment than younger age groups of caregivers. It can also be concluded that safety priority and workers' safe behaviour depend on the communication skills and workers' competences or awareness of specialty. The authors suggest that the established safety management system with the organisation, all related activities and procedures need to be reliable and a fully integrated part of the general management system at the organisation. As the previous research suggests (Järvis, 2013; Sepp et al., 2018; Järvis et al., 2016; Virovere, 2015), it is essential to set fundamental values within the organisation, which inspire and energise their people and help build trust that is vital for the opportunity to exchange experiences and knowledge, and to learn together. To provide quality care and to enhance patients' and caregivers' safety in Estonian nursing homes, managers should actively work to maintain such a working environment as well as to develop employees' multigenerational skills, which influence workers' communication and increase commitment to safety.

\section{REFERENCES}

Arora, N. \& Dhole, V. (2019). Generation Y: Perspective, engagement, expectations, preferences and satisfactions from workplace; a study conducted in Indian context. Benchmarking: An International Journal, 26(5), 1378-1140. https://doi.org/10.1108/BIJ-05-2018-0132

Atstaja, D., Susniene, R., \& Järvis, M. (2017). The Role of Economics in Education for Sustainable Development; The Baltic States' Experience. International Journal of Economic Sciences, VI(2), 1-29. https://doi.org/10.20472/ES.2017.6.2.001

Ahanchian, M., Emami, A. \& Armat, M. (2015). Conflict management styles among Iranian critical care nursing staff: A cross-sectional study. Dimensions of Critical Care Nursing 34(3), 140-145. https://doi.org/10.1097/DCC.0000000000000106

Alameddine, M., Saleh, S., \& Natafgi, N. (2015). Assessing health-care providers' readiness for reporting quality and patient safety indicators at primary health-care centers in Lebanon: a national cross-sectional survey. Human Resources for Health, 13(1), 13-37. https://doi.org/10.1186/s12960-015-0031-5

Arnold, S. L., \& Yue, S. (2012). Perception of age diversity in Singapore: Implications for managing a diverse workforce. Cheltenham, UK: Edward Elgar.

Chan, J. C. Y., Sit, E. N. M. \& Lau, W. M. (2014). Conflict management styles, emotional intelligence and implicit theories of personality of nursing students: a cross-sectional study. Nurse Education Today, 34(6), 934-939. https://doi.org/10.1016/j.nedt.2013.10.012

Cox, J., \& Holloway, M. (2011). Workshop on knowledge transfer in a multigenerational business environment. RMIC, 4, 23-33.

Foot, D. K., \& Stoffman, D. (1998). Boom, bust \& echo 2000: Profiting from the demographic shift in the new millennium. Toronto, ON: Macfarlane Walter \& Ross.

Glass, A. (2007). Understanding generational differences for competitive success. Journal of Industrial and Commercial Training, 39(2), 98-103. https://doi.org/10.1108/00197850710732424 
Gurses, A., Carayon, P., \& Wall, M. (2009). Impact of Performance Obstacles on Intensive Care Nurses Workload, Perceive Quality and Safety of Care, and Quality of Working Life. Health Services Research, 44(2), 422-443. https://doi.org/10.1111/j.1475-6773.2008.00934.x

Haight, J. M., Yokiro, P., Rost, K. M., \& Willmer, D. R. (2014). Safety Management Systems Comparing Contents and Impact. Safety Management, May, 44-51.

Halbwachs, M. (1980). The collective memory. New York, NY: Harper.

Hamdan, M. (2013). Measuring safety culture in Palestinian neonatal intensive care unit using the Safety Attitudes Questionnaire. Journal of Critical Care, 28(5), 886e7-886e14. https://doi.org/10.1016/j.jcrc.2013.06.002

Hansen, J. I. C. \& Leuty, M. E. (2012). Work values across generations. Journal of Career Assessment, 20(1), 34-52. https://doi.org/10.1177/1069072711417163

Harrington, L. C. \& Smith, M. (2015). Nursing Peer Review: A Practical, Nonpunitive Approach to Case Review. 2nd ed. Danvers, MA: HCPro.

Heydari, A., Kareshki, H. \& Armat, M.R. (2016). Is Nurses' Professional Competence Related to Their Personality and Emotional Intelligence? A Cross-Sectional Study. Journal of Caring Sciences, 5(2), 121132. https://doi.org/10.15171/jcs.2016.013

Hill, R. P. (2002). Managing across generations in the 21st century: Important Lessons from the Ivory Trenches. Journal of Management Inquiry, 11(1), 60-66. https://doi.org/10.1177/1056492602111020

Järvis, M., Virovere, A., \& Tint, P. (2016). Formal Safety versus Real Safety: Quantitative and Qualitative Approaches to Safety Culture - Evidence from Estonia. Proceedings of the Latvian Academy of Sciences. Section B: Natural, Exact, and Applied Sciences, 70(5), 269-277. https://doi.org/10.1515/prolas-2016$\underline{0042}$

Järvis, M. (2013). Assessment of the Contribution of Safety Knowledge to Sustainable Safety Management System in Estonian SMEs. PhD thesis, Tallinn University of Technology.

Kim, I. H., Geiger-Brown, J., Trinkoff, A. \& Muntaner, C. (2010). Physically demanding workloads and the risks of musculoskeletal disorders in homecare workers in the USA. Health and amp; Social Care Community, 18(5), 445-455. https://doi.org/10.1111/j.1365-2524.2010.00916.x

Kines, P. et al. (2011). Nordic Safety Climate Questionnaire (NOSACQ-50): A new tool for diagnosing occupational safety climate. International Journal of Industrial Ergonomics, 41(6), 634-646. https://doi.org/10.1016/j.ergon.2011.08.004

Krahn, H. J. \& Galambos, N. L. (2014). Work values and beliefs of 'Generation X' and 'Generation Y'. Journal of Youth Studies, 17(1), 92-112. https://doi.org/10.1080/13676261.2013.815701

Kuimet, K., Järvis, M. \& Virovere, A. (2016). Integrating Ergonomics Principles and Workplace Health Protection and Promotion to improve safety and health at work - evidence from Estonia. Agronomy Research, 14(2), 460-474.

Lambert, M. J. (2004). Leading a patient-safe organization. Chicago: Healthcare Administration Press.

Mannheim, K. (1952). The problem of generations. In P. Kecskemeti (Ed.), Essays on the sociology of knowledge, pp. 378-404. London: Routledge.

McDonald, K. S. \& Hite, L. M. (2008). The next generation of career success: Implications for HRD. Advances in Developing Human Resources, 10(1), 86-103. https://doi.org/10.1177/1523422307310116

McGonagle, A., Essenmacher, L., Hamblin, L., Luborsky, M., Upfal, M., Arnetz, J. (2016). Management Commitment to Safety, Teamwork, and Hospital Worker Injuries. Journal Hospital Administration, 5(6), 46-52. https://doi.org/10.5430/jha.v5n6p46

Moore, J. M., Everly, M. \& Bauer, R. (2016). Multigenerational Challenges: Team-Building for Positive Clinical Workforce Outcomes. OJIN: The Online Journal of Issues in Nursing, 21(2).

Ng, E. S., Schweitzer, L., \& Lyons, S. T. (2010). New generation, great expectations: A field study of the millennial generation. Journal of Business and Psychology, 25(2), 281-292. https://doi.org/10.1007/s10869-010-9159-4

Ng, E. S. \& Parry, E. (2016). Multigenerational research in human resource management. Research in Personnel and Human Resources Management, 34, 1-41. https://doi.org/10.1108/S0742730120160000034008

Ostrom, L., Wilhelmsen, C. \& Kaplan, B. (1993). Assessing safety culture, Nuclear Safety, 34(2), 163-172.

Pusette, A., Larsman, P., Eklöf, M. \& Törner, M. (2017). The relationship between patient safety climate and occupational safety climate in healthcare - A multi-level investigation. Journal of Safety Research, 61, 187-198. https://doi.org/10.1016/j.jsr.2017.02.020

Rasch, R. \& Kowske, B. (2012). Will millennials save the world through work? International generational differences in the relative importance of corporate social responsibility and business ethics to turnover intentions. In Managing the new workforce: International perspectives in the millennial generation, pp. 222-241. Cheltenham, UK: Edward Elgar Publishing.

Ratnapalan, S. \& Uleryk, E. (2014). Organizational Learning in Health Care Organizations. Systems, 2(1), 24-33. https://doi.org/10.3390/systems2010024 
Reeves, T. C. \& Oh, E. (2008). Generational differences. In J. M. Spector, M. D. Merrill, J. van Merrienboer, \& M. P. Driscoll (Eds.), Handbook of research on educational communications and technology (3rd ed., pp. 295-303). Mahwah, NJ: Lawrence Erlbaum.

Sepp, J. (2018). Development of a Reciprocal Health Care Model for Determination of Safety Level in the Nursing Homes in Estonia. European Journal of Economics and Business Studies, 4(3), 122-130. https://doi.org/10.2478/ejes-2018-0065

Sepp, J., Reinhold, K., Järvis, M., \& Tint, P. (2018). Human Factors and Ergonomics in Safety Management in Healthcare: Building New Relationships. Agronomy Research, 16(4), 1862-1876.

Sepp, J. \& Tint, P. (2017). The Components of Non-Punitive Environment in Nursing. Safety of Technogenic Environment, 8(1), 24-30. https://doi.org/10.1515/ste-2017-0004

Schuman, H. \& Scott, J. (1989). Generations and collective memories. American Sociological Review, 54(3), 359-381. https://doi.org/10.2307/2095611

Smola, K. W. \& Sutton, C. D. (2002). Generation differences: Revisiting generational work values for the new millennium. Journal of Organizational Behavior, 23(4), 363-382. https://doi.org/10.1002/job.147

Titlestad, I., Haugstveedt, A., Igland, J. \& Graue, M. (2018). Patient safety culture in nursing homes - a crosssectional study among nurses and nursing aides caring for residents with diabetes. BMC Nursing, 17, Article 36. https://doi.org/10.1186/s12912-018-0305-z

Twenge, J. M. (2010). A review of the empirical evidence on generational differences in work attitudes. Journal of Business and Psychology, 25(2), 201-210.

Twenge, J. M. \& Campbell, S. M. (2008). Generational differences in psychological traits and their impact on the workplace. Journal of Managerial Psychology, 23(8), 862-877. https://doi.org/10.1108/02683940810904367

Virovere, A. (2015). The Role of Management Values, Knowledge Management and Conflict Management for Improvement of Organisational Sustainability. Doctoral thesis, Tallinn University of Technology: Tallinn University of Technology Press, pp 219.

West, E., Maben, J. \& Rafferty, M. (2006). Nursing and Patient Outcomes: How Can Employers Provide the Right Environment for Nurses to Deliver High Quality Care? Harvard Health Policy Review, 7(1), 64-85.

Westman, J. W., Bergman, J. Z., Bergman, S. M. \& Daly, J. P. (2011). Are universities creating millennial narcissistic employees? An empirical examination of narcissism in business students and its implications. Journal of Management Education, 36(1), 5-32. https://doi.org/10.1177/1052562911408097

Woodhead, E. L., Northrop, L. \& Edelstein, B. (2014). Stress, social support, and burnout among long-term care nursing staff. Journal of Applied Gerontology, 35(1), 84-105. https://doi.org/10.1177/0733464814542465

Zohar, D. (2008). Safety climate and beyond: A multi-level multi-climate framework. Safety Science, 46(3), 376-387. https://doi.org/10.1016/j.ssci.2007.03.006

\section{AUTHORS' SHORT BIOGRAPHIES}

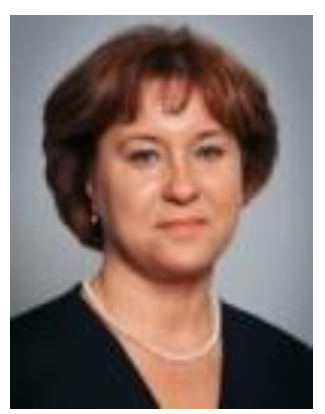

Jaana Sepp is the Head of the Educational Department at Tallinn Health Care College. She has two Master of Science degrees, one from Tallinn University as a psychologist (The Connection between the Motives for Joining the Defence Forces, Perceived Organizational Support and the Reasons for Leaving, 2008) and one from Tartu University as a sociologist (Evaluation of the Need for Psychometric Tests in the Inclusive Education by Teachers and School Psychologist, 2013).

At present, she is a $\mathrm{PhD}$ student of Tallinn University of Technology, Department of Business Administration and her topic is "Proactive Safety Management in Healthcare - Towards a Broader View of Wellbeing among Healthcare Employees".

She has 10 scientific publications and her $\mathrm{PhD}$ thesis is at the final stage.

E-mail: jaana.sepp@ttk.ee

ORCID iD: $\underline{\text { https://orcid.org/0000-0003-1624-8580 }}$ 


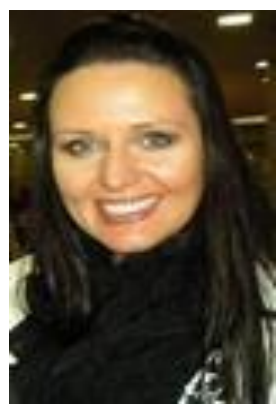

Marina Järvis is an Associate Professor of safety management at Tallinn University of Technology (TTU), School of Business and Governance. She defended her PhD in 2013 at TTU in business administration. She holds an MSc degree in occupational health from Bergen University, Norway. She has published 40 scientific papers; she has represented Estonia at the international $\mathrm{OH} \& \mathrm{~S}$ conferences many times and participated in relevant projects. Her research interests focus on safety culture, knowledge management in OH\&S; safety management system; occupational wellbeing.

E-mail: marina.jarvis@ taltech.ee

ORCID iD: https://orcid.org/0000-0002-4541-4632 